\title{
Without a Horizon
}

\author{
Fyodor A. Lukyanov
}

| DOI: 10.31278/1810-6374-2020-18-3-5-8

When the coronavirus pandemic paralyzed international life, everybody started saying that life had been divided into "before" and "after" and would never be the same. After the first shock wore off, something like stabilization set in: the form changes, of course, but the content remains pretty much the same. The global political agenda continues to hold sway, and as nations withdraw from the viral anabiosis, old problems are reemerging worldwide.

The perception is different again, and this time it is probably closer to reality. To put it short: all the processes that were underway before the crisis have accelerated significantly. The world has not turned upside down, but the farther these processes go, the less it will resemble the one everyone has got accustomed to over the last several decades. Constant pervasive uncertainty will become a distinctive feature of the coming years. One can argue that there is nothing new about it and that this phenomenon has been talked about for quite a while. This is true, but now the trend is assuming a different quality.

The coronavirus is vivid proof. Its nature and behavior are still a riddle, and although medics and relevant services have gained much experience over the past few months, they are still groping their way. This explains why everybody talks about vaccines and drugs optimistically, but at the same time very cautiously and vaguely. Fresh outbreaks occur here and there, some countries announce new lockdowns, while others are reimposing restrictions lifted in late spring and early summer. The authorities may be blowing on cold water, but they will continue to do so.

This means that the nervous pace of international communication will now become the norm and may be suddenly interrupted by another epidemiological crisis. This will seriously affect the planning of international activities, not even by narrowing the horizon, but leading away from it, making one watch his step, rather than look ahead on the road. 
The main victim of this year's events is universal mobility, which had reached its peak by the third decade of the current century. Even if, as everyone hopes, the borders begin to open at some point, they may be closed again at any moment, like it or not. The harder travel becomes, the greater the impact on the infrastructure associated with it from transport or hotels to the entire service sector, which depends on a massive influx of people. This does not mean the end of tourism and business trips, but their scale will inevitably shrink. Also, the forced transition to online mode of activities last spring naturally makes one wonder whether mobility is needed at all.

National borders are assuming a new role: they close the space if not of personal security, then at least of the current rules and relative freedom of movement. As some commentators noted at the peak of the pandemic, nationalism had become neither ethnic, nor civil, but territorial in nature-those permanently living in the same territory are believed to be less of a threat to each other than any visitors. Of course, the experience of the acute phase of the pandemic should not be absolutized, but it will not pass without a trace either.

The predictability of international behavior in the post-war era was determined by the presence of institutions that effectively limited the actions of states and kept them within certain bounds. Now they are running dry as the global environment has changed dramatically and the foundations of their successful functioning are gone (the balance of power ended with the end of the Cold War, and the attempt at domination by one country has failed). In the coming years, international institutions will continue to wither and some may even disappear completely (although, as a rule, this process is held off by bureaucratic inertia-it is easier to create a new structure than to abolish an existing one).

International cooperation will not stop. This is simply impossible in an interconnected world, and it will remain so. But it will no longer be based on global structures issuing rules for its participants. There are loud calls for saving/reviving multilateral approaches in order to prevent the world from sliding towards political Darwinism and the struggle of all against all. Multilateralism is habitually understood as a return to more or less universal institutions of the previous period, but in the coming era multilateralism will be completely different. It will mean the ability of several countries (three and more, as may be necessary) to combine efforts in order to address specific issues. Those parties that are needed and important for a particular task will be engaged. Such interaction continues as long as the 


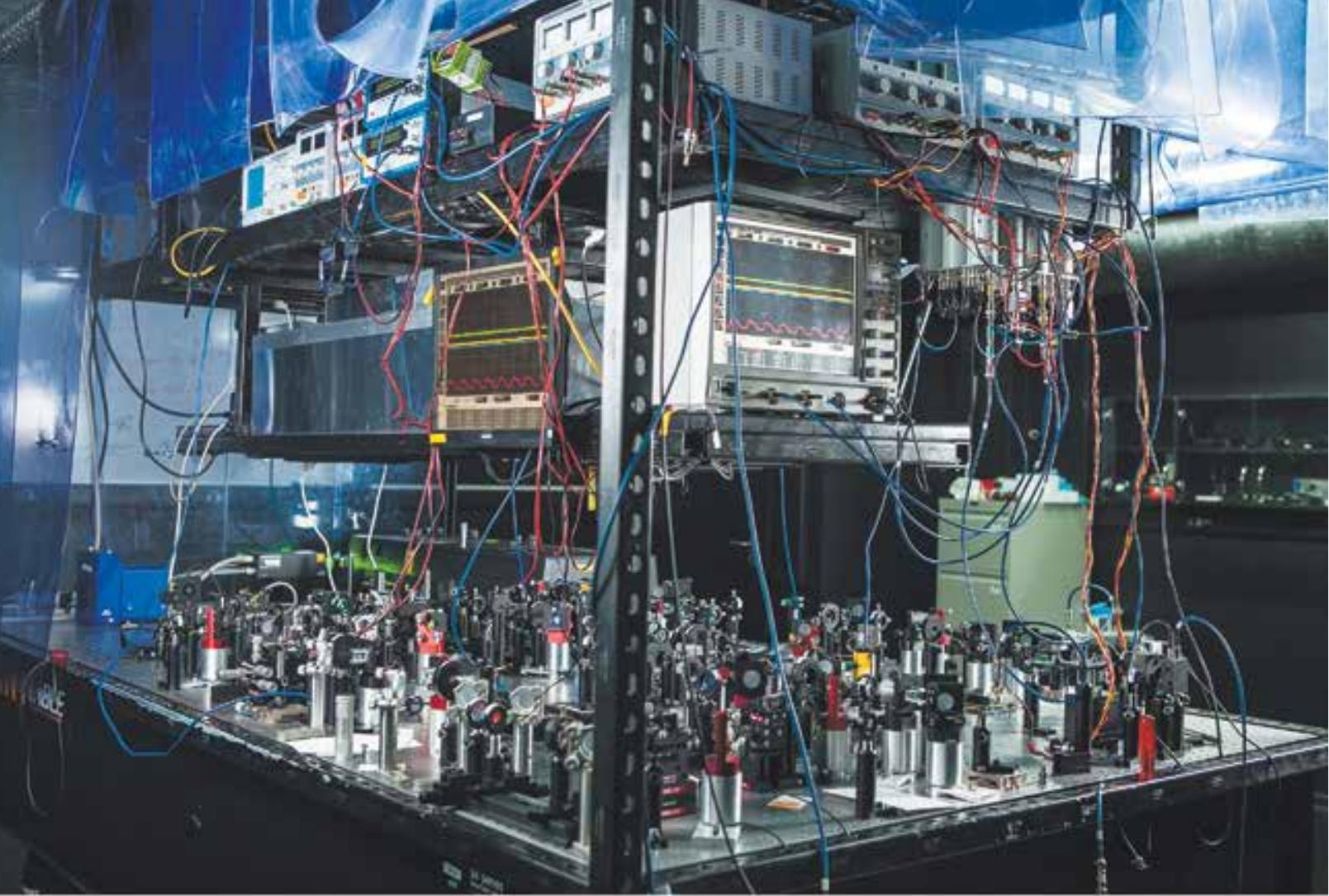

Quantum technologies embodied in microchips and lasers have already changed our world at least once. Now they are about to change it again by controlling matter and light at the level of individual particles. The second quantum revolution will be new materials and ultra-secure communications, superlative accuracy in measurement and efficiency in calculation. The Russian Quantum Center is steadily riding on the crest of this new technological wave.

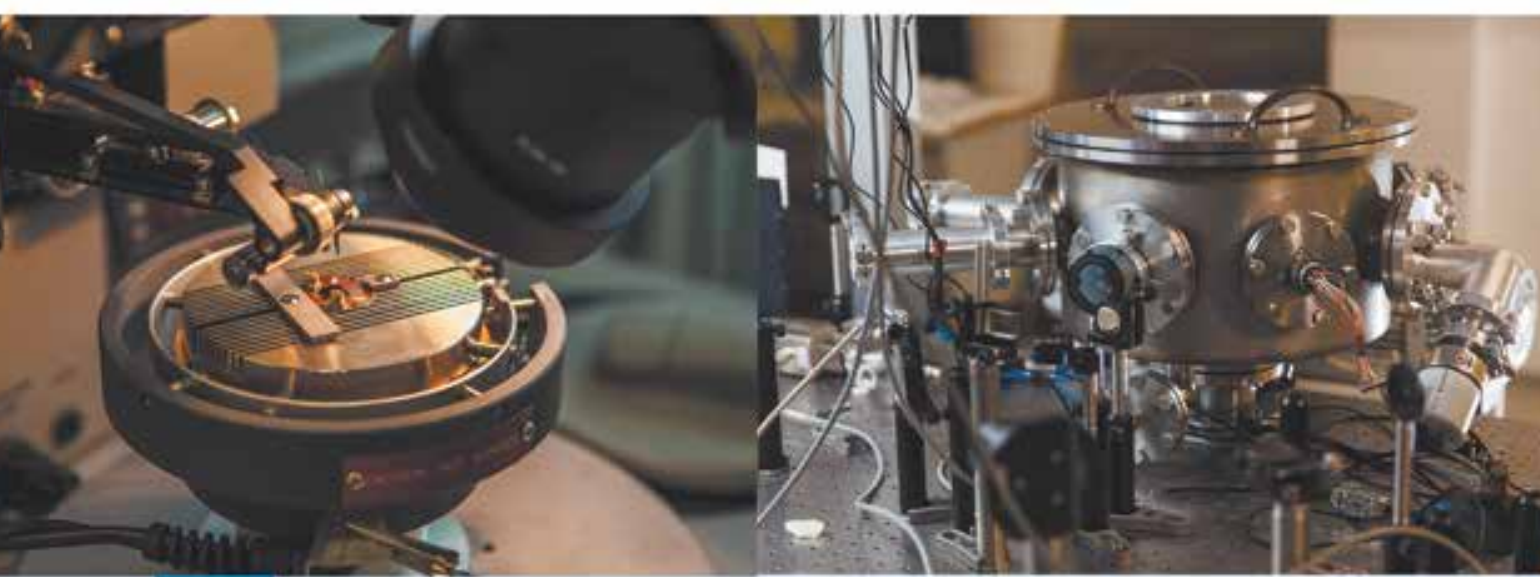


task remains relevant, but once it is basis of interaction. As the imporsolved, the configuration changes. tance of states in the world system

This is a much more complex and variable system than the one that was used during the heyday of globalization, but there is no alternative. In this system, everything will depend more than ever on the strength, stability and effectiveness of every state, at least because these qualities will determine the outcome of bargaining in each particular case. Bargaining in this model of multilateralism becomes the increases, and this is exactly what the pandemic has highlighted, they will face an ever-growing demand for resilience. This suggests primarily the ability to build harmonious relations with their own societies and only then set sights on the international stage. There are enough examples of how the absence of such harmony leads to upheavals, and there will be more and more of them in the future. 